\title{
QUEBRANDO TABUS SOBRE OS JOGOS TEATRAIS DE VIOLA SPOLIN
}

\author{
RAMALDES, Karine ${ }^{1}$ \\ Mestre em Performances Culturais- UFG \\ kramaldesatriz@gmail.com
}

A metodologia dos jogos teatrais sistematizada pela autora e diretora de teatro improvisacional norte americana Viola Spolin (1906-1994), é bastante comentada e utilizada no meio teatral e educacional. Muitos fazedores e estudiosos de teatro já entraram em contato com tal abordagem, mas nem todos se debruçaram em se aprofundar na mesma. Talvez, por este motivo, em corredores de diversos congressos realizados em universidades brasileiras, é possível perceber uma visão dos jogos teatrais de Viola Spolin como uma abordagem apenas para iniciação teatral, e não só isso, também uma diminuição do real potencial desta abordagem.

Antes de iniciar este diálogo é preciso esclarecer que prefiro não denominar os jogos teatrais de Viola Spolin como metodologia, mas sim como abordagem. Pois Viola Spolin sistematiza uma forma de abordagem dos jogos teatrais que pode ser utilizada em qualquer jogo teatral, porém, como esta abordagem será desenvolvida dependerá da metodologia de cada orientador dos jogos. Deste modo, compreendo a metodologia como forma muito pessoal de colocar em prática as ideias abordadas, por isso a mesma dependerá de cada orientador.

Os jogos teatrais foram sistematizados por Viola Spolin, numa abordagem baseada na improvisação, sendo que para esta autora improvisação é:

Jogar um jogo; predispor-se a solucionar um problema sem qualquer preconceito quanto à maneira de solucioná-lo; permitir que tudo no

\footnotetext{
${ }^{1}$ Karine Ramaldes é atriz e professora de teatro, mestre em Performances Culturais, pela Universidade Federal de Goiás (UFG). Graduada em Artes Cênicas pela UFG. É professora da Secretaria de Educação do Estado de Goiás atuando na Escola SESI Planalto, e professora da Secretaria Municipal de Educação e Esporte de Goiânia, atuando na Gerência de Projetos Educacionais da referida secretaria. Tem publicado artigos nacionais e internacionais sobre jogos teatrais, teatro/ educação, performances culturais e o conceito de experiência. Revista "O Teatro Transcende" Departamento de Artes - CCEAL da FURB - ISSN 2236-6644 - Blumenau, Vol. 21, № 1, p. 53 - 64, 2016
} 
ambiente (animado ou inanimado) trabalhe para você na solução do problema; não é a cena, é o caminho para a cena; uma função predominante do intuitivo; entrar no jogo traz para as pessoas de qualquer tipo a oportunidade de aprender teatro; é "tocar de ouvido"; é processo, em oposição a resultado; nada de invenção ou "originalidade" ou "idealização"; uma forma, quando entendida, possível para qualquer grupo de qualquer idade; colocar um objeto em movimento entre os jogadores como um jogo; solução de problemas em conjunto; a habilidade para permitir que o problema de atuação emerja da cena; um momento nas vidas das pessoas sem que seja necessário um enredo ou estória para a comunicação; uma forma de arte; transformação... processo vivo. (SPOLIN, 2006, p. 341)

Na improvisação, não se utiliza combinações prévias, mas sim todos os elementos que cercam os jogadores no momento do jogo (aqui/agora), elementos imaginários, sensitivos e corporais que surgem da relação entre os jogadores e da relação dos jogadores com o ambiente. O processo é mais valorizado do que o produto final: se o jogo vai se transformar em uma peça teatral apresentável a um público externo, isso pouco importa. O mais importante é o processo de aprendizagem do jogador, o que ele conseguiu assimilar do e no jogo.

Existe uma senda muito particular no processo da aprendizagem humana que possibilita uma experiência de auto-investigação do indivíduo, cuja proposta não se situa na área da terapia, mas sim no domínio do laboratório dramático teatral, e que tem nos jogos, nas improvisações, em exercícios específicos e na atitude reflexiva o seu centro de gravidade. (JANUZELLI, 2006, p.7. itálico do autor)

O laboratório teatral, a pesquisa é importante para todo e qualquer ator, pois permite a ele a investigação do próprio corpo e do seu potencial criativo, levando-o à novas descobertas e possibilidades. A abordagem dos jogos teatrais de Viola Spolin vai ao encontro desta perspectiva de pesquisa, ação e reflexão.

Viola Spolin sistematiza a abordagem dos jogos teatrais a partir de três essências, assim denominadas por ela: Foco, Instrução e Avaliação. O Foco é apresentado por Spolin, como o ponto de concentração para onde o jogador deve dirigir toda a sua atenção no momento do jogo. Com a atenção direcionada para 
determinado ponto, o jogador consegue, com maior facilidade, manter a concentração durante o desenvolvimento do jogo, pois sua energia está direcionada. Nas palavras de Spolin, foco é:

Atenção dirigida e concentrada numa pessoa, objeto ou acontecimento específico dentro da realidade do palco; enquadrar uma pessoa, objeto ou acontecimento no palco; é a âncora (o estático) que torna o movimento possível. (SPOLIN, 2006, p. 340)

O foco proposto por Spolin trabalha diretamente com a concentração em cena, concentração esta também considerada indispensável para grandes mestres do teatro, como Constantin Stanislavski, Antonin Artaud, Jerzy Grotowski. Antonio Januzelli, doutor em Artes e professor da Escola de Comunicação da Universidade de São Paulo, traz de modo objetivo os principais ensinamentos destes grandes mestres em seu livro A aprendizagem do ator (2006), destacando que para Stanislavski a concentração é:

O desenvolvimento da concentração intensiva sobre círculos de atenção: objetos, pessoas, espaços etc.; a atenção deslocando-se sempre em companhia da corrente de energia, criando assim uma linha infinita, ininterrupta. A linha interior de movimentação é a base da plasticidade. (JANUZELLI, 2006, p.16-17)

É a concentração que cria a ambientação para a criação do ator. Em seus próprios escritos, Stanislavski destaca a importância de um ator concentrado em cena, ressaltando que "a criatividade é, antes de tudo, a completa concentração de toda a natureza do ator." (STANISLAVSKI, 1997, p. 17). Para Stanislavski, a concentração em cena é fundamental, sendo esta diretamente relacionada com a criatividade. Sem uma verdadeira concentração não é possível um ator criativo.

Para Artaud: "por meio do conhecimento físico, qualquer ator pode aumentar a densidade interna e o volume dos seus sentimentos e com esse domínio orgânico conseguir uma expressão plena." (JANUZELLI, 2006, p.21). Somente será possível o conhecimento físico se houver foco, concentração no trabalho proposto, e é a partir disso que se atingirá a expressão plena, proposta por Artaud. 
"Grotowski advoga o ator "santo" - aquele indivíduo que se engaja na investigação de si mesmo para se tornar um criador." (JANUZELLI, 2006, p.24. aspas do autor.) Grotowski vem fechar o ciclo de ideias dos outros autores aqui apresentados, pois para se investigar algo, necessário se faz ter foco, concentração, e a partir da concentração podemos atingir a criação. É possível, então, perceber que o foco apontado por Spolin, trabalha diretamente com a concentração, que é indispensável para qualquer trabalho teatral.

A Instrução, proposta por Spolin durante a realização do jogo teatral contribui bastante com a práxis (ação - reflexão - ação) no momento do jogo. A instrução se trata de indicações do orientador do jogo (no momento do jogo) para que os jogadores permaneçam no foco. São realizadas de acordo com as situações que vão surgindo na ação de jogar. A Instrução gera uma parceria entre orientador e jogador, e esta parceria durante o jogo é essencial para o bom andamento do trabalho. Segundo Spolin:

[...] A instrução atinge o organismo total. As expressões usadas na instrução surgem espontaneamente a partir do que está acontecendo no palco, e são dadas no momento em que os jogadores estão em ação. Este é um método para manter o jogador e diretor em contato. (SPOLIN, 2010a, p.25)

Ou seja, Spolin também direciona sua abordagem para a relação ator/ diretor. Sendo as instruções relevantes para todo e qualquer processo de construção cênica, pois as criações precisam ser lapidadas pelo diretor teatral, pelo olhar do outro. Grotowski se referindo à relação ator/diretor afirma que: "[...] o diretor se torna um guia que o ajuda (ator) a resolver as dificuldades que possa encontrar e a vencer as inibições e condicionamentos." (JANUZELLI, 2006, p.28. parênteses meu.). Quando o diretor se utiliza de instruções dentro do desenvolvimento criativo, se torna um parceiro do ator, permitindo fluidez em todo o processo.

A Avaliação, sugerida por Spolin após o jogo, também auxilia os jogadores a perceberem a necessidade de permanecerem dentro do foco durante a ação de jogar, pois o foco irá contribuir na solução dos problemas que surgem no momento da ação. Revista "O Teatro Transcende" Departamento de Artes - CCEAL da FURB - ISSN 2236-6644 - Blumenau, Vol. 21, № 1, p. 53 - 64, 2016 
Ao final de cada jogo, uma avaliação do mesmo é proposta, uma avaliação não no sentido de bom ou ruim, mas que vai ao encontro à resposta de se os jogadores conseguiram manter o foco, além de ponderarem sobre suas dificuldades e facilidades em jogo.

Segundo Januzelli, a proposta de trabalho com o ator, de Stanislavski tem como um dos seus objetivos "despertar no ator a consciência de suas próprias necessidades pessoais e das potencialidades dos instrumentos técnicos de sua arte: capacidades intelectuais, físicas, emocionais e espirituais." (JANUZELLI, 2006, p.11). A avaliação após laboratórios e/ou jogos teatrais ajudam o ator a terem essa consciência apontada por Stanislavski, pois a avaliação é o momento de refletirem e verbalizarem sobre a ação executada. Para Spolin a avaliação é um "método de crítica através do envolvimento com o problema, e não de um envolvimento interpessoal." (SPOLIN, 2006, p.336). O envolvimento interpessoal faz parte da abordagem proposta por Spolin, entretanto no momento da avaliação o que importa refletir é sobre como foi o envolvimento com o problema proposto pelo jogo, por isso a autora afirma que não se trata de envolvimento interpessoal.

\begin{abstract}
Os jogos são baseados em problemas a serem solucionados. O problema é o objeto do jogo que proporciona o foco. As regras do jogo teatral incluem a estrutura dramática (Onde/ Quem/ O Que) e o foco, mais o acordo de grupo. Para ajudar os jogadores a alcançar uma solução focalizada para o problema, Spolin sugere o princípio da instrução, por meio do qual o jogador é encorajado a manter a atenção no foco. Dessa forma, o jogo é estruturado através de uma intervenção pedagógica na qual o coordenador/ professor e o aluno/atuante se tornam parceiros de um projeto artístico. (KOUDELA in SPOLIN, 2010b, p.22)
\end{abstract}

Inerente a cada jogo existe um problema de atuação que deve ser solucionado, a forma de solucioná-lo vai variar entre os jogadores. Jogar é uma proposta de interagir com determinado meio, com o intuito de solucionar determinados problemas de atuação que são colocados anteriormente ao jogo, sendo que novos problemas de atuação podem surgir no meio do jogo e o jogador precisará se empenhar em resolver também os novos problemas que surgem. Ao jogar e lidar com o problema no aqui e 
agora, inicia-se a construção de um repertório próprio de solução de problemas de cena que auxiliará o jogador nos jogos futuros.

O problema de atuação é um desafio aos jogadores, que devem solucionar o problema durante a execução do jogo, interagindo com os colegas de cena. Spolin afirma: "[...] quando um problema é solucionado, tem-se como resultado um conhecimento orgânico da técnica teatral." (SPOLIN, 2006, p. 346). Ainda ao definir "problema de atuação", Spolin pontua-o como um "problema que prefigura um resultado, desenvolvimento de técnicas teatrais, jogos teatrais." (SPOLIN, 2006, p. 346). Portanto, percebo que o problema proposto em cada jogo é primordial para que o jogador apreenda e aprenda a técnica teatral. Quando soluciona o problema, consequentemente vai se apropriando da arte teatral. Spolin compreende que:

\footnotetext{
As técnicas teatrais estão longe de serem sagradas. Os estilos do teatro mudam radicalmente com o passar dos anos. A realidade da comunicação é muito mais importante do que o método usado. Os métodos se alteram para atender às necessidades de tempo e lugar (...)

As técnicas não são artifícios mecânicos - um saquinho de truques devidamente rotulados, a serem tirados pelo ator quando necessário. Se o ator não for extremamente intuitivo, tal rigidez no ensino que negligencia o desenvolvimento interior, estará invariavelmente refletida no espetáculo.

Quando um ator sente "na carne" que há muitas maneiras de fazer e dizer uma coisa, as técnicas virão (como deveriam) a partir do eu total. (SPOLIN, 2010a, p. 20)
}

As técnicas teatrais, nesta perspectiva, são aprendidas de forma orgânica porque ocorrem naturalmente por meio da vivência do jogador em cena. Na construção de um espetáculo teatral também surgem vários problemas de atuação que devem ser solucionados pelos atores em parceria com o diretor do espetáculo. Estes problemas de atuação podem ser solucionados a partir de propostas de jogos, pois sair da proposta do espetáculo e depois retomá-la com o intuito de resolver problemas do próprio espetáculo pode ser um caminho profícuo para novas criações e possibilidades. Mais uma vez retomando Stanislavski com os seus objetivos do trabalho com o ator, o mesmo afirma que é necessário: "ajudar o ator a descobrir quais são os seus obstáculos e aprender a lidar com eles." (JANUZELLI, 2006, p.11), a 
solução de problemas inerente aos jogos propostos por Spolin trabalham diretamente com esse aprendizado: de como lidar com os obstáculos de atuação que surgem.

É na relação prática entre o jogador e o jogo, que o sujeito encontrará possibilidades de solucionar o problema proposto, e ao se engajar em solucionar tal problema, o jogador acaba por se entregar por inteiro à experiência de jogar, envolvendo emoção, sensibilidade e pensamento, ou seja se envolve de forma orgânica.

Manter o foco no momento do trabalho teatral, receber instruções durante o desenvolvimento dos trabalhos teatrais, refletir e avaliar as possibilidades exploradas em salas de ensaios não me parece ser procedimentos apenas para iniciação teatral e sim para todos os atores iniciantes e/ou iniciados. A partir destas relações realizadas até o momento, percebo que os jogos teatrais se apresentam como colaboradores de todo o processo de preparação de atores.

Várias outras abordagens realizadas por Viola Spolin a partir dos jogos teatrais são pertinentes para qualquer trabalho teatral, como a fisicalização ${ }^{2}$, que segundo Spolin é:

Mostrar e não contar: a manifestação física de uma comunicação; a expressão física de uma atitude; usar a si mesmo para colocar um objeto em movimento; dar vida ao objeto... representar é contar, fisicalizar é mostrar; uma maneira visível de fazer uma comunicação subjetiva. (SPOLIN, 2006, p.340)

O ator, mesmo quando profissional precisa estar atento para não se deixar levar por uma atuação mecânica e cheia de clichês. O que propõe os exercícios de

\footnotetext{
2 Ingrid Dormien Koudela, tradutora dos livros de Viola Spolin para o português, em seu livro Jogos Teatrais (2002, p. 51), na nota de rodapé, escreve a observação de que fizeram uma revisão da tradução da palavra "physicalization", considerando o termo "corporificação" como mais correto do que "fisicalização". Porém neste artigo continuarei trabalhando com o termo "fisicalização", para não causar nenhuma confusão, já que as traduções que utilizo ainda consideram este termo.
} 
fisicalização de Spolin é justamente a ação orgânica ${ }^{3}$ do ator, onde o corpo inteiro está envolvido no ato teatral, é trazer para o concreto o que está apenas na cabeça do ator. A fisicalização proposta por Spolin também vai ao encontro do trabalho com a pantomima, já que:

\begin{abstract}
Atualmente a pantomima é considerada um estilo dentro da mímica. Ela tem como característica contar uma história, na qual há um relativo respeito pelo tempo e espaço reais, com temática cotidiana, normalmente sem fala. $[\ldots]$

Para o desenvolvimento técnico da pantomima é importante apurar a consciência do próprio corpo e também a percepção do espaço e do ritmo. Para tanto, usam-se exercícios de observação de si e do outro, detalhamento dos movimentos da ação escolhida, consciência do peso e tamanho dos objetos, entre outros. (KOUDELA; JUNIOR, 2015, p.138)
\end{abstract}

O trabalho de fisicalização explora justamente o respeito ao tempo e espaço reais a partir da relação do corpo com o espaço, trazendo para o espaço a construção de objetos imaginários, o que envolve o desenvolvimento da consciência corporal, além da percepção do espaço e do ritmo. Este trabalho pode ser verificado em vários jogos de Spolin, como no cabo de guerra, pular corda, jogo de bola, descritos em diversos livros da autora, como no livro Jogos Teatrais na Sala de Aula (2010b), no tópico Jogos de Transformação. O foco destes jogos é o trabalho com os objetos imaginários trazendo a realidade dos mesmos, um trabalho minucioso e laborioso.

A fisicalização pode ser trabalhada além dos objetos, pode-se fisicalizar um personagem, um sentimento, emoção. Januzelli ao falar sobre "o autodesvendamento" proposto por Grotowski, traz o trecho descrevendo as "associações", onde podemos fazer relação com a fisicalização de Spolin:

São o retorno a uma recordação exata, que emerge não só da mente mas de todo o corpo; o ator deve relacionar as ações concretas com uma lembrança, pois as recordações são sempre reações físicas: foi a pele que

\footnotetext{
3 Tanto no teatro como na dança, o termo orgânico é usado como sinônimo de "vivo" ou "crível". Quem introduziu na língua do trabalho teatral do século XX foi Stanislávski. Para o reformador russo, organichnost (organicidade) e organicheskij (orgânico) eram qualidades essenciais nas ações de um ator, a premissa para que um espectador reagisse com um "eu acredito" absoluto. (BARBA e SAVARESE, 2012, p. 206)
} 
não esqueceu, foram os olhos que fixaram, os ouvidos que gravaram. Elas são simples pensamentos, por isso não podem ser calculados. (JANUZELLI, 2006, p.28)

No processo de fisicalização, a recordação necessita estar além da mente, precisa se expressar pelo corpo. As próprias instruções sugeridas por Spolin nestes jogos dizem: "Vejam o objeto entre vocês!; Use o corpo todo!; Intensifique este movimento!" (SPOLIN, 2010b, 87-89) É uma relação direta e orgânica corpo/mente, onde o trabalho de percepção corporal está sempre presente.

Os jogos teatrais de Viola Spolin podem ser abordados em qualquer nível de processo teatral, desde a iniciação a preparação de ator profissional, mudando apenas as formas de abordagens, o que vai depender muito do conhecimento e habilidade do orientador. A própria autora, Viola Spolin, escreveu um livro dedicado exclusivamente aos diretores teatrais O Jogo Teatral no Livro do Diretor (2010), onde utiliza termos mais comuns a esta área profissional.

Considero sim um caminho profícuo trabalhar a iniciação teatral a partir da abordagem de Viola Spolin, porém reduzir todo o trabalho de Spolin somente a isso é um tanto quanto desrespeitoso. Viola Spolin, junto a seu filho Paul Sills (1927-2008) sistematizou a abordagem dos jogos teatrais a partir da experiência prática também com companhias teatrais, ou seja, a partir da preparação de atores. Viola Spolin é reconhecida nos meios profissionais dos Estados Unidos por sua ligação com o The Second City, uma importante companhia de teatro de Chicago, criada em 1959 e dirigida por seu filho, o diretor teatral, Paul Sills. Entre 1960 e 1965, Spolin trabalhou como preparadora de atores na referida companhia, período em que publicou o seu primeiro livro, Improvisation for the Theater, em 1963. Paul Sills é conhecido como coautor da abordagem dos jogos teatrais de Viola Spolin, pois também preparava os atores das companhias em que atuou a partir da denominada metodologia improvisacional dos jogos teatrais, ajudando sua mãe a pensar e a elaborar tal abordagem, assinando com ela a terceira edição de Improvisação para o Teatro, publicada nos Estados Unidos em 1999, depois da morte de Spolin. 
Improvisation for Theater foi editado pela primeira vez em 1963. O sistema foi desenvolvido em grande parte na Young Actors Company, em Hollywood, durante mais de dez anos. Spolin recebeu influências de Stanislavski, que cita no livro, e de Neva Boyd, com a qual teve um treinamento em jogos, arte de contar histórias, danças e canções folclóricas. Esteve ligada ao The Compass Players (1955-1957), em Chicago que foi o primeiro elenco profissional de teatro de improvisação dos Estados Unidos, sob a direção de David Sheperd e Paul Sills. Este último, filho de Spolin, participou diretamente na formulação do sistema de Jogos Teatrais e fundou em 1959 o Second City. (KOUDELA, 2002, p. 40)

A abordagem dos jogos teatrais de Viola Spolin foi concebida na prática, na ação e relação entre os jogadores e os jogos propostos. O The Second City continua ativo nos dias atuais e se tornou uma grande empresa, mantendo as escolas de improviso. Existem sedes em Chicago (Illinois-EUA), Los Angeles (Califórnia-EUA) e Toronto (Ontário-Canadá). O site oficial do The Second City (http://www.secondcity.com) aponta-o como o maior centro de treinamento para a improvisação e atuação dos Estados Unidos, formador de muitos atores famosos deste país, que trabalham principalmente com a comédia. Atores ligados à companhia produziram várias séries de TV, como a Saturday night live, e prosseguem até os dias de hoje com as apresentações teatrais baseadas no improviso. Esta importante companhia de teatro improvisacional carrega, em sua história, as marcas deixadas por Paul Sills e Viola Spolin.

Realizo esta pequena retomada histórica da origem dos Jogos Teatrais de Viola Spolin para refletirmos a respeito. Se na origem da elaboração desta abordagem Viola Spolin trabalhava com atores profissionais e também pessoas que nunca fizeram teatro antes, esses indícios estão presentes na sua abordagem. A autora teve um olhar especial ao desenvolver a abordagem para conseguir atingir os diversos fazedores de teatro, iniciantes ou iniciados.

Viola Spolin propõe uma abordagem que consegue chegar a todos, pois utiliza termos mais próximos da realidade de qualquer um. Um exemplo é a denominação Revista "O Teatro Transcende" Departamento de Artes - CCEAL da FURB - ISSN 2236-6644 - Blumenau, Vol. 21, № 1, p. 53 - 64, 2016 
que utiliza ao se referir à estrutura dramática básica. Spolin utiliza os termos: Quem? Onde? O quê? Perguntas, geralmente feitas para os atores por qualquer diretor teatral, não necessariamente desta forma, mas na montagem de um espetáculo o diretor aguça os atores a cada vez mais descobrirem os personagens que interpretam: modo de andar, agir, olhar etc. o que nada mais é o "Quem", trabalhado por Spolin.

Também na montagem de um espetáculo, geralmente o diretor traz a sua visão de onde se passa a ação dramática, conciliada com a visão do autor do texto e dos atores, então o "Onde", proposto por Spolin está sendo trabalhado, pois a partir do momento em que o ator visualiza o quem e onde da sua ação, enriquece suas possibilidades cênicas e outros modos de criação vão surgindo.

Não menos importante é compreender o quê se passa nas cenas do espetáculo. Muitas vezes nas leituras iniciais essa discussão é feita pelo diretor com os atores, trazendo as visões de todos para a mesa de debate, pois somente com o quê se passa claro, os atores poderão desenvolver ações mais concretas. As descobertas do o quê, de um espetáculo, não necessariamente acontecem apenas na discussão verbal do texto, muitas vezes podem surgir na ação dos atores, no momento dos ensaios, onde estão envolvidos completamente.

Os elementos: Quem? Onde? O que?, presentes na abordagem de Spolin, são importantes para o trabalho de qualquer ator, sendo ele iniciante ou não. Viola Spolin, na elaboração de sua abordagem parte de pesquisas de grandes estilos e autores teatrais, por isso podemos fazer relação direta entre a proposta de Spolin e as propostas destes grandes mestres do teatro:

Viola Spolin, diretora de teatro e pedagoga, possibilitou com suas reflexões práticas profundas bases para o teatro improvisacional norte-americano. Nele estão impressas as técnicas do cabaret alemão, da commedia dell'arte, da atuação brechtiana e de muitos dos conceitos de experiência ativa no trabalho do ator de Stanislavski... (CAMARGO, 2010, p. 2) 
A abordagem de Spolin se apresenta a partir de uma densidade metodológica e filosófica e não apenas uma relação de exercícios para serem aplicados, sem um corpus metodológico e/ou filosófico de maior densidade que os envolve. Reconhecer a relevância de tal abordagem é necessário, mesmo que não se utilize a mesma, e para reconhecê-la necessário se faz debruçar sobre a mesma. É factível afirmar que a metodologia dos jogos teatrais de Viola Spolin não é uma abordagem apenas para a iniciação teatral, muito se engana e pouco conhece tal abordagem, quem assim pensa. Utilizar tal metodologia como modo de trabalhar a iniciação também é um caminho profícuo, porém a abordagem de Spolin vai além disso.

\section{REFERÊNCIAS}

CAMARGO, Robson Corrêa de. O Jogo Teatral e sua Fortuna Crítica... . Revista Fênix. vol.7, Ano VII no 1. jan./fev./mar./abril 2010.

SPOLIN, Viola. Improvisação para o Teatro. 5a edição. Tradução: Ingrid Dormien Koudela e Eduardo José de Almeida Amos. São Paulo: Ed. Perspectiva, 2006.

O Jogo Teatral no Livro do Diretor. 2a edição. Tradução: Ingrid Dormien Koudela e Eduardo Amos. São Paulo: Ed. Perspectiva, 2010a. Jogos Teatrais na sala de aula. 2a edição. Tradução: Ingrid Dormien Koudela. São Paulo: Ed. Perspectiva, 2010b.

BARBA, Eugenio; SAVARESE, Nicola. A Arte Secreta do Ator - Um Dicionário de Antropologia Teatral. São Paulo: Realizações Editora, 2012.

JANUZELLI, Antonio. A aprendizagem do ator. 3ạ edição. São Paulo: Ática, 2006.

KOUDELA, Ingrid Dormien. Jogos Teatrais. São Paulo: Ed. Perspectiva, 2002.

KOUDELA, Ingrid Dormien; JÚNIOR, José Simões de Almeida (Coord.). Léxico de Pedagogia do Teatro. São Paulo: Perspectiva, 2015.

STANISLAVSKI, Constantin. Manual do Ator. São Paulo: Martins Fontes, 1997.

http://www.secondcity.com. Acessado em 10 de maio de 2016. 